УДК 576.895.751.4

DOI 10.18413/2658-3453-2020-2-3-205-218

\title{
ФАУНА ПУХОЕДОВ (РНТНIRAРТЕRА: MALLOPHAGA) \\ ВОРОБЬИНООБРАЗНЫХ ПТИЦ В Г. ВОРОНЕЖЕ
}

\section{FAUNA OF THE CHEWING LICE (PHTHIRAPTERA: MALLOPHAGA) OF PASSERINE BIRDS IN VORONEZH}

\author{
С.П. Гапонов, Р.Т. Теуэльде \\ S.P. Gaponov, R.T. Tewelde \\ Воронежский государственный университет, \\ Россия, 394006, г. Воронеж, Университетская пл., 1 \\ Voronezh State University, \\ 1 Universitetskaya Sq, Voronezh, 394006, Russia \\ E-mail: Gaponov2003@mail.ru
}

\begin{abstract}
Аннотация
Цель исследования состояла в изучении фауны пухоедов (Phthiraptera: Mallophaga) воробьинообразных птиц в урбосистемах г. Воронежа. В результате исследований 23 видов птиц обнаружено 22 вида пухоедов из 6 родов и 3 семейств (сем. Menoponidae, Ricinidae, Philopteridae). К подотряду Amblycera относятся 8 видов пухоедов (36.37\%) и к подотряду Ischnocera - 14 видов $(63.63 \%)$. Впервые для Воронежской области и Центрального Черноземья выявлено 16 видов пухоедов: Philopterus fringillae Scopoli, 1772, Ph. capillatus Złotorzycka, 1964, Ph. guttatus (Denny, 1852), Ph. corvi (Linnaeus, 1758), Ph. picae Denny, 1842, Ph. microsomaticus (Piaget, 1871), Ph. pallescens (Denny, 1842), Brueelia uncinosa (Burmeister, 1838), B. marginata Burmeister, 1838, B. varius (Burmeister, 1838), Ricinus rubeculae Schrank, 1776, R. elongatus (Olfers, 1816), Myrsidea rustica Giebel, 1874, M. anathorax (Nitzsch, 1866), Menacanthus agilis Nitzsch, 1866, M. curucca (Schrank, 1776). Самые высокие показатели индекса встречаемости отмечены для $R$. rubeculae (5.00), M. curucca (4.84), R. elongatus (3.89), Ph. capillatus (3.77), Ph. microsomaticus (3.50), M. agilis (3.41). Наиболее интенсивно хозяева были инфестированы пухоедами Brueelia borini Lunkaschu, 1970, B. uncinosa, B. uncinosa и Ph. pallescens.
\end{abstract}

\section{Abstract}

In 2017-2020, the fauna of chewing lice (Phthiraptera: Mallophaga) found in 23 passerine bird species were studied in urban ecosystems of Voronezh, Russia. 22 species of chewing lice belonging to 6 genera of 3 families (Menoponidae, Ricinidae, and Philopteridae) were identified. Of these, 8 species (36.37\%) belonged to suborder Amlycera, and 14 species $(63.63 \%)$ to suborder Ischnocera. 16 species of chewing lice were identified for the first time in Voronezh and the Central Black Soil Region of Russia: Philopterus fringillae Scopoli, 1772, Ph. capillatus Złotorzycka, 1964, Ph. guttatus (Denny, 1852), Ph. corvi (Linnaeus, 1758), Ph. picae Denny, 1842, Ph. microsomaticus (Piaget, 1871), Ph. pallescens (Denny, 1842), Brueelia uncinosa (Burmeister, 1838), B. marginata Burmeister, 1838, B. varius (Burmeister, 1838), Ricinus rubeculae Schrank, 1776, R. elongatus (Olfers, 1816), Myrsidea rustica Giebel, 1874, M. anathorax (Nitzsch, 1866), Menacanthus agilis Nitzsch, 1866, M. curucca (Schrank, 1776). The highest prevalence was registered for $R$. rubeculae (5.00), M. curucca (4.84), R. elongatus (3.89), Ph. capillatus (3.77), Ph. microsomaticus (3.50), and M. agilis (3.41). The hosts most intensively infested with the chewing lice were: Brueelia borini Lunkaschu, 1970, $B$. uncinosa, B. uncinosa, and Ph. pallescens.

Ключевые слова: воробьинообразные, пухоеды, интенсивность инфестации, встречаемость, паразито-хозяинные связи.

Keywords: passerine birds, chewing lice, infestation intensity, abundance, host-parasite links. 


\section{Введение}

Пухоеды (Mallophaga) - мелкие бескрылые облигатно эктопаразитические насекомые с неполным превращением и тремя личиночными стадиями, относящиеся к отряду Phthiraptera; характерной морфологической чертой их является выраженная крупная голова, ширина которой больше переднегруди [Frank, Kritsky, 2002]. Хозяевами большинства пухоедов являются птицы; некоторые освоили шерсть млекопитающих [Galloway, 2019]. У пухоедов - паразитов птиц на лапках выражены два коготка, у паразитов зверей - один коготок. Ротовые органы, расположенные внизу головы, приспособлены к питанию перьями, волосами, эпидермальными чешуями, в ряде случаев - лимфой и кровью хозяев [Johnson, Clayton, 2003]. В целом пухоеды обладают высокой специфичностью в отношении хозяев [Балашов, 2001]. Несмотря на широкое распространение этих паразитов, их фауна и экология изучены неравномерно и неполно. Как правило, исследовались пухоеды некоторых семейств или экологических групп птиц и млекопитающих, либо отдельных регионов. Опубликованы списки пухоедов птиц Польши, Болгарии, Молдовы, Литвы, Латвии, Белоруси, Украины, Туркмении, Румынии, Венгрии, Чехии, Испании, Греции, Северной Америки и некоторых других стран [Волькис, Панавайте, 1965; Гринберге, 1974; Федоренко и др., 1975; Федоренко, 1976, 1977, 1978, 1987; Emerson, 1972a, 1972b; Złotorzycka, 1980, 1983; Soler-Cruz, BenitezRodriguez, 1989; Жук, 2009; Ilieva, 2003; Adam, Sandor, 2004; Sychra et al., 2011; Diakou et al., 2017]. Фауна пухоедов и их связи с хозяевами исследованы в ряде регионов бывшего СССР и России [Благовещенский, 1940a, 1940б, 1948, 1950, 1951; Васюкова, 1986; Чернобай, 1972; Васюкова, Комаров, 1997]. На территории Северо-запада России отмечено 76 видов пухоедов из 26 родов [Благовещенский, 1940a; Федоренко, 1987; Толстенков и др., 2009; Малышева, Толстенков, 2018]. Для Закавказья отмечено 93 вида пухоедов [Благовещенский, 1940a, 1940б], Центрального Предкавказья - 103 вида [Ляхова, Котти, 2010; Тебуева, 2011], Западной Сибири - 103 [Благовещенский, 1950], Беларуси - 132 [Жук, 2009]. О.Н. Степановой [2016] обследовано 360 особей птиц 13 оседлых видов воробьинообразных на территории Якутии, выявлено 27 видов пухоедов из 6 родов. В Сибири выявлено 47 видов пухоедов из 6 родов из трех семейств (Ancistronidae, Laemobothriidae, Pseudomenoponidae) подотряда Amblycera, 42 вида пухоедов из 5 родов и двух семейств отряда Ischnocera, 42 вида пухоедов из 10 родов и трех семейств (Phthirapteridae, Laemobothriidae, Pseudomenoponidae) отряда Amblycera [Степанова, 2018a, 2018б, 2019a, 2019б; Stepanova, 2018]. На Куршской косе с перелетных птиц были собраны пухоеды 35 видов 8 родов (семейства Menoponidae (24 видами 3 родов), Ricinidae (4 видов 1 рода) и Philopteridae (7 видов 4 родов) [Малышева, Толстенков, 2018]. Исследованы пухоеды неворобьиных птиц окрестностей Ростова и Ростовской области [Малышева и др., 2018а, 2018б], обнаружено 29 видов пухоедов, 16 из них оказались новыми для территории России.

На территории Центрального Черноземья пухоеды остаются практически неизученной группой эктопаразитов. В «Кадастре беспозвоночных животных Воронежской области» [2005] указаны четыре вида пухоедов, паразитирующих на степном орле: Degeeriella discocephalus Burmeister, 1838, Falcolipeurus suturalis Rudow, 1869, Craspedorrhinchus aquilinus Denny, 1842, Colpocephalum impressum Rudow, 1869 [Федоренко, Харченко, 1980]. Для г. Воронежа выполнены исследования по фауне пухоедов полевого и домового воробьев, выявлено 6 видов пухоедов: Menacanthus eurysternus Giebel, 1874, Ricinus fringillae De Geer, 1778, Sturnidoecus ruficeps Giebel, 1866, Brueelia subtilis Giebel, 1874, B. borini Lunkaschu, 1970, Philopterus montani Złotorzycka, 1964 [Теуэльде, Гапонов, 2020]. Исходя из этого, мы поставили цель - исследовать фауну пухоедов воробьинообразных птиц на территории г. Воронежа. 


\section{Материал и методы исследования}

В 2017-2020 гг. на территории г. Воронежа было обследовано 4713 птиц, принадлежащих к 23 видам из отряда воробьинообразных (Passeriformes) (табл. 1). Всего собрано 750 особей пухоедов. Сбор пухоедов с птиц осуществляли с помощью пинцета в пробирки с $70^{\circ}$-ным этанолом. Всё оперение птицы осматривали в определенном порядке (головной отдел, шея, спина, перья крыльев). Разборку гнезд, фиксацию и изготовление временных (в глицерине) и постоянных (в канадском бальзаме) препаратов осуществляли в лаборатории по общепринятым методикам [Гапонов и др., 2009; Гапонов, 2011].

Таблица 1

Table 1

Виды обследованных воробьинообразных птиц и количество видов пухоедов, обнаруженных на них, на территории г. Воронежа в 2017-2020 гг.

Species of the examined passerine birds and a number of associated chewing lice species in the territory of Voronezh in 2017-2020

\begin{tabular}{|c|c|c|c|c|}
\hline \multirow[b]{2}{*}{ № } & \multirow[b]{2}{*}{ Виды птиц } & \multicolumn{3}{|c|}{ Пухоеды (кол-во видов) } \\
\hline & & $\begin{array}{c}\text { Подотряд } \\
\text { Amblycera } \\
\text { Kellogg, } 1896\end{array}$ & $\begin{array}{c}\text { Подотряд } \\
\text { Ischnocera } \\
\text { Kellogg, } 1896\end{array}$ & Всего \\
\hline 1 & Riparia riparia (Linnaeus, 1758) & 1 & 1 & 2 \\
\hline 2 & Delichon urbicum (Linnaeus, 1758) & 0 & 1 & 1 \\
\hline 3 & Hirundo rustica Linnaeus, 1758 & 1 & 0 & 1 \\
\hline 4 & Passer domesticus Linnaeus, 1758 & 2 & 5 & 7 \\
\hline 5 & P. montanus Linnaeus, 1758 & 2 & 4 & 6 \\
\hline 6 & Fringilla coelebs Linnaeus, 1758 & 1 & 0 & 1 \\
\hline 7 & Erithacus rubecula (Linnaeus, 1758) & 2 & 0 & 2 \\
\hline 8 & Muscicapa striata (Pallas, 1764) & 1 & 0 & 1 \\
\hline 9 & Turdus pilaris Linnaeus, 1758 & 1 & 1 & 2 \\
\hline 10 & T. philomelos Brehm, 1831 & 1 & 0 & 1 \\
\hline 11 & Sturnus vulgaris Linnaeus, 1758 & 1 & 0 & 1 \\
\hline 12 & Pica pica (Linnaeus, 1758) & 1 & 1 & 2 \\
\hline 13 & Corvus frugilegus Linnaeus, 1758 & 1 & 1 & 2 \\
\hline 14 & C. monedula (Linnaeus, 1758) & 1 & 2 & 3 \\
\hline 15 & C. cornix (Linnaeus, 1758) & 1 & 2 & 3 \\
\hline 16 & Motacilla alba Linnaeus, 1758 & 1 & 0 & 1 \\
\hline 17 & Sylvia borin Boddaert & 0 & 3 & 3 \\
\hline 18 & Curruca (Sylvia) communis (Latham, 1787). & 1 & 0 & 1 \\
\hline 19 & Parus major Linnaeus, 1758 & 1 & 1 & 2 \\
\hline 20 & Cyanistes (Parus) caeruleus (Linnaeus, 1758) & 1 & 0 & 1 \\
\hline 21 & Remiz pendulinus (Linnaeus, 1758) & 1 & 0 & 1 \\
\hline 22 & Phylloscopus sibilatrix (Bechstein, 1793) & 1 & 1 & 2 \\
\hline
\end{tabular}

Для видовой диагностики пухоедов использовали «Определитель насекомых Европейской части СССР» [Бей-Биенко, 1964, 1970], определители Д.И. Благовещенского [1940, 1964], И.А. Федоренко [1983, 1987], Р.Д. Прайса и др. [Price et al., 2003], а также сводки по отдельным родам и видам [Clay, Hopkins, 1951, 1954; Złotorzycka, 1964, 1980, 1983; Price, 1975, 1977; Sychra et al., 2014]. При идентификации материала были также использованы постоянные препараты пухоедов из коллекции кафедры зоологии и паразитологии Воронежского государственного университета (Россия) и Гуэлфского университета (Канада). Материал хранится на кафедре зоологии и паразитологии 
Воронежского госуниверситета. Номенклатуру пухоедов и таксономический состав семейств приводим в соответствии c R. Price et al. [2003]. Классификация типов паразитохозяинных связей дана по Медведеву [2002]: виды пухоедов, известные только с одного вида хозяев, являются моноксенными, с нескольких видов хозяев из одного рода олигоксенными, с хозяев нескольких родов из одного семейства - мезоксенными, с хозяев из нескольких семейств одного отряда - поликсенными, и с хозяев, принадлежащих разным отрядам, - эвриксенными видами. Рассчитан индекс встречаемости (ИВ; $\mathrm{P}$ - prevalence) - процент объектов, на которых обнаружены эктопаразиты данного вида или группы видов, по отношению к общему числу проанализированных проб.

\section{Результаты и их обсуждение}

В результате исследований 23 видов воробьинообразных птиц (см. табл. 1) на территории г. Воронежа обнаружено 22 вида пухоедов из 6 родов и 3 семейств (табл. 2). Все пухоеды собраны с птиц, в гнездовой подстилке - не обнаружены.

Таблица 2

Table 2

Видовой состав пухоедов воробьинообразных птиц в г. Воронеже (2017-2020 гг.)

и основной паразитологический индекс (ИВ (Р) - индекс встречаемости)

Species composition of chewing lice of passerine birds in Voronezh (2017-2020) and the main parasitological index $(\mathrm{P}-$ prevalence $)$

\begin{tabular}{|c|c|c|c|}
\hline № & Виды пухоедов & Кол-во особей & ИВ (Р) \\
\hline & Подотряд Amblycera Kellogg, 1896 & & \\
\hline & Сем. Menoponidae Mjoberg, 1910 & & \\
\hline 1 & Menacanthus curucca (Schrank, 1776) & 12 & 4.84 \\
\hline 2 & M. eurysternus Giebel, 1874 & 73 & 1.28 \\
\hline 3 & M. agilis Nitzsch, 1866 & 10 & 3.41 \\
\hline 4 & Myrsidea anathorax (Nitzsch, 1866) & 60 & 2.79 \\
\hline \multirow[t]{2}{*}{5} & M. rustica Giebel, 1874 & 2 & 1.11 \\
\hline & Cем. Ricinidae Neumann, 1890 & & \\
\hline 6 & Ricinus elongatus (Olfers, 1816) & 65 & 3.89 \\
\hline 7 & R. fringillae De Geer, 1778 & 98 & 1.67 \\
\hline \multirow[t]{3}{*}{8} & R. rubeculae Schrank, 1776 & 3 & 5.00 \\
\hline & Подотряд Ischnocera Kellogg, 1896 & & \\
\hline & Сем. Philopteridae Burmeister, 1838 & & \\
\hline 9 & Sturnidoecus ruficeps Giebel, 1866 & 36 & 1.75 \\
\hline 10 & Brueelia subtilis Giebel, 1874 & 44 & 2.00 \\
\hline 11 & B. borini Lunkaschu, 1970 & 76 & 0.53 \\
\hline 12 & B. varius (Burmeister, 1838) & 19 & 0.40 \\
\hline 13 & B. marginata Burmeister, 1838 & 4 & 0.50 \\
\hline 14 & B. uncinosa (Burmeister, 1838) & 10 & 0.39 \\
\hline 15 & Philopterus pallescens (Denny, 1842) & 42 & 0.69 \\
\hline 16 & Ph. microsomaticus (Piaget, 1871) & 33 & 3.50 \\
\hline 17 & Ph. picae Denny, 1842 & 79 & 2.55 \\
\hline 18 & Ph. corvi (Linnaeus, 1758) & 14 & 0.78 \\
\hline 19 & Ph. guttatus (Denny, 1852) & 2 & 0.22 \\
\hline 20 & Ph. capillatus Złotorzycka, 1964 & 6 & 3.77 \\
\hline 21 & Ph. montani Złotorzycka, 1964 & 54 & 2.13 \\
\hline \multirow[t]{2}{*}{22} & Ph. fringillae Scopoli, 1772 & 8 & 0.40 \\
\hline & Всего: & 750 & 4.20 \\
\hline
\end{tabular}


Подотряд Amblycera Kellogg, 1896

Сем. Menoponidae Mjoberg, 1910

Род Menacanthus Neumann, 1912

1. Menacanthus curucca (Schrank, 1776)

Известен как поликсенный вид, паразитирующий на 14 видах и подвидах птиц, относящихся к двум семействам воробьинообразных [Price и др., 2003]. Отмечен в Калининградской области на садовой славке (Sylvia borin Boddaert) [Толстенков и др., 2009] и в Центральном Предкавказье на большой синице [Тибуева, 2011]. В г. Воронеже отмечен на Curruca (Sylvia) communis (Latham, 1787) (ИВ 4.84). Указывается впервые для Воронежской области.

2. Menacanthus eurysternus Giebel, 1874

В сводке Р. Прайса и др. [Price et al., 2003] указан как эвриксенный паразит, связанный с 176 видами и подвидами птиц из 35 семейств из отрядов воробьинообразных и дятлообразных. В России выявлен на сороке в Якутии [Степанова, 2016] и в Центральном Предкавказье [Тебуева, 2011]. На территории г. Воронежа отмечен на четырёх видах хоязев: Passer domesticus Linnaeus, 1758 (ИВ 5.60), Passer montanus Linnaeus, 1758 (ИВ 3.00), Remiz pendulinus (Linnaeus, 1758) (ИВ 10.00) и Pica pica (Linnaeus, 1758) (ИВ 0.25). С учетом всех хозяев ИВ 1.28.

3. Menacanthus agilis Nitzsch, 1866

В Греции обнаружен в оперении Cettia cetti (Temminck, 1829) [Diakou et al.,2017]. В г. Воронеже обнаружен на двух видах хозяев - Phylloscopus sibilatrix (Bechstein, 1793) (ИВ 17.50) и Muscicapa striata (Pallas, 1764) (ИВ 6.25). С учетом обоих видов птиц-хозяев ИВ 3.41. Указывается впервые для Воронежской области.

Род Myrsidea Waterston, 1915

4. Myrsidea anathorax (Nitzsch, 1866)

Типичным хозяином служит галка, однако, на остальных представителях врановых отмечался неоднократно [Тебуева, 2011]. Олигоксенный вид. В условиях г. Воронежа обнаружен в оперении галки (Corvus monedula (Linnaeus, 1758)) (ИВ 1.14), грача (Corvus frugilegus Linnaeus, 1758) (ИВ 6.66) и серой вороны (Corvus cornix (Linnaeus, 1758)) (ИВ 4.70). С учетом всех хозяев ИВ 2.79. Указывается впервые для Воронежской области.

5. Myrsidea rustica Giebel, 1874

Это широко распространенный эктопаразит деревенской ласточки (отмечался неоднократно и на городской ласточке), встречающийся во многих регионах России и Европы. В г. Воронеже обнаружен на деревенской ласточке (Hirundo rustica Linnaeus, 1758) (ИВ 1.11). Указывается впервые для Воронежской области.

\section{Семейство Ricinidae Neumann, 1890}

Род Ricinus De Geer, 1778

6. Ricinus elongatus (Olfers, 1816)

В качестве типичного хозяина указывался черный дрозд [Васюкова, Комаров, 1997]. В г. Воронеже отмечен как эктопаразит птиц трех видов: рябинника Turdus pilaris Linnaeus, 1758 (ИВ 1.11), певчего дрозда Turdus philomelos Brehm, 1831 (ИВ 4.50) и обыкновенного скворца Sturnus vulgaris Linnaeus, 1758 (ИВ 6.52). С учетом всех видовхозяев ИВ 3.89. Указывается впервые для Воронежской области.

7. Ricinus fringillae De Geer, 1778

В г. Воронеже этот пухоед обнаружен на 8 видах воробьиных птиц: ласточкебереговушке Riparia riparia (Linnaeus, 1758) (ИВ 0.87), полевом воробье Passer montanus Linnaeus, 1758 (ИВ 2.66), домовом воробье Passer domesticus Linnaeus, 1758 (ИВ 1.20), зяблике Fringilla coelebs Linnaeus, 1758 (ИВ 1.96), зарянке Erithacus rubecula (Linnaeus, 1758) (ИВ 5.00), белой трясогузке Motacilla alba Linnaeus, 1758 (ИВ 3.57), большой синице 
Parus major Linnaeus, 1758 (ИВ 1.04) и лазоревке Cyanistes (Parus) caeruleus (Linnaeus, 1758 ) (ИВ 2.89). Поликсенный вид. С учетом всех видов-хозяев ИВ 1.67.

8. Ricinus rubeculae Schrank, 1776

В г. Воронеже этот пухоед обнаружен на зарянке Erithacus rubecula (Linnaeus, 1758). Моноксенный вид. Встречается нечасто ИВ 5.00. Указывается впервые для Воронежской области.

Подотряд Ischnocera Kellogg, 1896

Семейство Philopteridae Burmeister, 1838

Род Sturnidoecus Eichler, 1944

\section{Sturnidoecus ruficeps Giebel, 1866}

На территории г. Воронежа выявлен на полевом воробье Passer montanus Linnaeus, 1758 (ИВ 1.60; и домовом воробье Passer domesticus Linnaeus, 1758 (ИВ 2.00). Олигоксенный вид. ИВ с учетом обоих видов хозяев 1.75 .

\section{Род Brueelia Keler, 1936}

10. Brueelia subtilis Giebel, 1874

На территории г. Воронежа обнаружен на полевом воробье Passer montanus Linnaeus, 1758 (ИВ 2.00) и домовом воробье Passer domesticus Linnaeus, 1758 (ИВ 2.00). Олигоксенный вид. ИВ с учетом обоих видов хозяев 2.00.

11. Brueelia borini Lunkaschu, 1970

На территории г. Воронежа обнаружен на полевом воробье Passer montanus Linnaeus, 1758 (ИВ 0.33), домовом воробье Passer domesticus Linnaeus, 1758 (ИВ 0.20) и садовой славке Sylvia borin (Boddaert, 1783) (ИВ 2.07). ИВ с учетом трех видов хозяев 10.13.

12. Brueelia varius (Burmeister, 1838)

Олигоксенный вид, отмечающийся на видах рода Corvus [Ляхова, 2005, 2006]. На территории г. Воронежа обнаружен на галке Corvus monedula (Linnaeus, 1758) (ИВ 0.23) и граче Corvus frugilegus Linnaeus, 1758 (ИВ 1.67). ИВ с учетом обоих видов хозяев 0.40. Указывается впервые для Воронежской области и Центрального Черноземья.

13. Brueelia marginata Burmeister, 1838

Моноксенный вид, паразитирующий на рябиннике, иногда отмечается на случайных хозяевах - дроздах других видов [Благовщенский, 1951]. На территории г. Воронежа обнаружен на рябиннике Turdus pilaris Linnaeus, 1758 (ИВ 0.50). Указывается впервые для Воронежской области и Центрального Черноземья.

14. Brueelia uncinosa (Burmeister, 1838)

На территории г. Воронежа обнаружен на серой вороне Corvus cornix (Linnaeus, 1758) (ИВ 0.39). Моноксенный вид. Указывается впервые для Воронежской области и Центрального Черноземья.

\section{Род Philopterus Nitzsch, 1818}

15. Philopterus pallescens (Denny, 1842)

На территории г. Воронежа обнаружен на большой синице Parus major Linnaeus, 1758 (ИВ 0.69). Моноксенный вид. Указывается впервые для Воронежской области и Центрального Черноземья.

16. Philopterus microsomaticus (Piaget, 1871)

На территории г. Воронежа обнаружен на деревенской ласточке Hirundo rustica Linnaeus, 1758 (ИВ 3.33) и городской ласточке Delichon urbicum (Linnaeus, 1758) (ИВ 3.64). Мезоксенный вид. ИВ с учетом обоих видов хозяев: 0.69. Указывается впервые для Воронежской области и Центрального Черноземья. 
17. Philopterus picae Denny, 1842

Моноксенный вид, хотя в некоторых регионах известны находки на граче и серой вороне [Тебуева, 2011]. На территории г. Воронежа обнаружен на сороке Pica pica (Linnaeus, 1758) (ИВ 2.55). Указывается впервые для Воронежской области и Центрального Черноземья.

18. Philopterus corvi (Linnaeus, 1758)

Основным хозяином является ворон, однако, отмечался на серой вороне, галке, граче [Благовещенский, 1940, 1948, 1951; Вольскис, Панавайте, 1965]. На территории г. Воронежа обнаружен на серой вороне Corvus cornix (Linnaeus, 1758) (ИВ 0.78). Олигоксенный вид. Указывается впервые для Воронежской области и Центрального Черноземья.

19. Philopterus guttatus (Denny, 1852)

На территории г. Воронежа обнаружен на галке Corvus monedula (Linnaeus, 1758) (ИВ 0.22). Моноксенный вид. Указывается впервые для Воронежской области и Центрального Черноземья.

20. Philopterus capillatus Złotorzycka, 1964

На территории г. Воронежа обнаружен на Ficedula hypoleuca (Pallas, 1764) (ИВ 3.77). Моноксенный вид. Указывается впервые для Воронежской области и Центрального Черноземья.

21. Philopterus montani Złotorzycka, 1964

На территории г. Воронежа обнаружен на полевом воробье Passer montanus Linnaeus, 1758 (ИВ 3.66) и домовом воробье Passer domesticus Linnaeus, 1758 (ИВ 1.20). Олигоксенный вид. ИВ с учетом обоих видов хозяев: 2.13.

22. Philopterus fringillae Scopoli, 1772

Моноксенный вид, хотя в ряде регионов использует случайных хозяев: зяблика [Чвак, Харамбура, 1972], деревенскую ласточку и скворца [Мустафаева, 1972]. На территории г. Воронежа обнаружен на домовом воробье Passer domesticus Linnaeus, 1758 (ИВ 0.40). Указывается впервые для Воронежской области и Центрального Черноземья.

В некоторых случаях отдельные виды пухоедов оказываются на случайных (нетипичных) хозяевах из других семейств птиц (M. agilis, R. elongatus, B. borini) вследствие вероятного переноса их поликсенными видами мух-кровососок (форезия). При высокой численности ряда видов птиц и их повышенной концентрации в городской среде возрастает число контактов между хозяевами как одного вида, так и разных видов. Это способствует обмену пухоедами, в том числе и неспецифичными для данного хозяина. В этих условиях, по-видимому, облегчается форезия пухоедов на поликсенных видах мухкровососок. Следует отметить, что В.А. Догель [1949] указывал на двойственную природу паразитофауны перелетных птиц, которая складывается из паразитов, полученных на зимовке и паразитов, приобретенных в местах гнездования, а также она формируется и из паразитов мигрирующих птиц (паразитов-убиквистов) [Догель, Навцевич, 1936; Догель, 1949]. Как во время перелетов, так и в периоды гнездования (северные широты) и зимовки (южные широты) между птицами разных видов неизбежно происходит обмен пухоедами. В местах совместного обитания птицы могут носить до $25 \%$ неспецифических для них паразитов [Дубинин, 1948]. Судьба паразитов может при этом быть различной. Зачастую они в течение короткого времени после перелета обнаруживаются на необычных хозяевах, а затем погибают, не завершая жизненный цикл. Наличие среди пухоедов поликсенных видов означает, что специфичность может иметь экологический характер.

\section{Выводы}

1. В результате исследований 23 видов воробьинообразных птиц на территории г. Воронежа обнаружено 22 вида пухоедов из 6 родов и 3 семейств (сем. Menoponidae, 
Ricinidae, Philopteridae). К подотряду Amblycera относятся 8 видов пухоедов (36.37 \%) и к подотряду Ischnocera - 14 видов (63.63 \%).

2. Впервые для Воронежской области и Центрального Черноземья выявлено 16 видов пухоедов: Philopterus fringillae Scopoli, 1772, Ph. capillatus Złotorzycka, 1964, Ph. guttatus (Denny, 1852), Ph. corvi (Linnaeus, 1758), Ph. picae Denny, 1842, Ph. microsomaticus (Piaget, 1871), Ph. pallescens (Denny, 1842), Brueelia uncinosa (Burmeister, 1838), B. marginata Burmeister, 1838, B. varius (Burmeister, 1838), Ricinus rubeculae Schrank, 1776, R. elongatus (Olfers, 1816), Myrsidea rustica Giebel, 1874, M. anathorax (Nitzsch, 1866), Menacanthus agilis Nitzsch, 1866, M. curucca (Schrank, 1776). Таким образом, для региона в настоящее время известно 22 вида пухоедов, паразитирующих на воробьинообразных птицах.

3. Наиболее высокий индекс встречаемости отмечен для $R$. rubeculae (5.00), M. curucca (4.84), R. elongatus (3.89), Ph. capillatus (3.77), Ph. microsomaticus (3.50), M. agilis (3.41). Наиболее интенсивно хозяева были инфестированы пухоедами Brueelia borini Lunkaschu, 1970, B. uncinosa, B. uncinosa и Ph. pallescens. С эпидемиологической точки зрения опасность представляют пухоеды, расцарапывающие кожные покровы и питающиеся лимфой и кровью хозяина, в частности в условиях Воронежа это M. curucca, $R$. rubeculae и $R$. elongatus.

4. В некоторых случаях отдельные виды пухоедов оказываются на случайных (нетипичных) хозяевах из других семейств птиц (M. agilis, R. elongatus, B. borini). При высокой численности ряда видов птиц и их повышенной концентрации в городской среде возрастает число контактов между хозяевами как одного, так и разных видов. Это способствует обмену пухоедами, в том числе и неспецифичными для данного хозяина. В этих условиях, по-видимому, облегчается форезия пухоедов на поликсенных видах мухкровососок.

\section{Список литературы}

1. Балашов Ю.С. 2001. Специфичность паразито-хозяинных связей членистоногих с наземными позвоночными. Паразитология, 35 (6): 473-489.

2. Бей-Биенко Г.Я. (общ. ред.). 1964. Определитель насекомых Европейской части СССР. T. 1. Низшие, древнекрылые, с неполным превращением. Москва-Ленинград, Наука, 936 с.

3. Благовещенский Д.И. 1940a. Mallophaga с птиц Талыша. Паразитологический сборник, (8): 25-90.

4. Благовещенский Д.И. 1940б. Фауна СССР. Определитель пухоедов (Mallophaga) домашних животных. М., 88c.

5. Благовещенский Д.И. 1948. Mallophaga с птиц Барабинских озер. Паразитологический сборник, (10): 259-294.

6. Благовещенский Д.И. 1950. Mallophaga с птиц Барабинских озер. Паразитологический сборник, (12): 87-122.

7. Благовещенский ДИ. 1951. Mallophaga Таджикистана. Паразитологический сборник, (13): $272-327$.

8. Благовещенский Д.И. 1964. Определитель насекомых Европейской части СССР. Т. 1. М.-Л., Наука: 309-323.

9. Васюкова Т.Т. 1986. Пухоеды (Mallophaga) водно-болотных птиц Якутии. Якутск, 116 с.

10. Васюкова Т.Т., Комаров Ю.Е. 1997. Материалы к фауне пухоедов и перьевых клещей некоторых видов птиц республики Северная Осетия - Алания. Кавказский орнитологический вестник, (9): 5-19.

11. Волькис Г.И., Панавайте М.А. 1965. Материалы к фауне пухоедов птиц Литовской ССР. Труды Академии наук Литовской ССР, (38): 97-107.

12. Гапонов С.П. 2011. Паразитология. Воронеж, Издательский Дом ВГУ, 732 с.

13. Гапонов С.П., Хицова Л.Н., Солодовникова О.Г. 2009. Методы паразитологических исследований. Воронеж, ВГУ, 180 с. 
14. Гринберге А.Р. 1974. Данные о пухоедах врановых птиц в Латвии. Латвийская энтомология, (16): 14-15.

15. Догель В.А. 1949. Биологические особенности паразитофауны перелетных птиц. Известия АН СССР, Серия биологическая, (1): 99-107.

16. Догель В.А., Навцевич Н.Д. 1936. Паразитофауна городской ласточки. К вопросу о происхождении паразитофауны перелетных птиц. Ученые записки ЛГУ, Серия биологическая, 7 (3): 80-113.

17. Дубинин В.Б. 1948. Исследование адаптаций эктопаразитов. II. Экологические адаптации перьевых клещей и пухоедов. Паразитологический сборник Зоологического института АН СCCP, 9: 191-222.

18. Жук Е.Ю. 2009. Фаунистические комплексы пухоедов птиц Беларуссии. Труды Ставропольского отделения Русского энтомологического общества, (5): 55-56.

19. Кадастр беспозвоночных животных Воронежской области. 2005. Воронеж, ВГУ, 825 с.

20. Ляхова О.М. 2006. Пухоеды (Mallophaga) Центрального Предкавказья. B кн.: Материалы 1 Всероссийского совещания по кровососущим насекомым. Санкт-Петербург: 114-116.

21. Ляхова О.М., Котти Б.К. 2010. Пухоеды (Mallophaga: Insecta) на птицах в Центральном Предкавказье. Паразитология, 44 (5): 461-474.

22. Малышева О.Д., Толстенков О.О. 2018. Пухоеды (Insecta, Phthiraptera) перелетных птиц Куршской косы. Паразитология, 52 (2): 118-136.

23. Малышева О.М., Забашта А.В., Толстенков О.О. 2018. К фауне пухоедов (Insecta: Phthiraptera) птиц (Aves: Falconiformes, Strigiformes) Нижнего Дона, Россия. Кавказский энтомологический бюллетень, 14 (1): С. 11-18.

24. Малышева О.Д., Забашта А.В., Толстеноков О.О. 2018. К фауне пухоедов (Phthiraptera) птиц Нижнего Дона, Россия. Пухоеды неворобьиных. Часть 1. Кавказский энтомологический бюллетень, 14 (2): 131-139.

25. Медведев С.Г. 2002. Особенности распространения и паразито-хозяинных связей блох (Siphonaptera). Энтомологическое обозрение, 81(3): 737-753.

26. Мустафаева 3.А. 1972. Эктопаразиты синантропных и домашних птиц Азербайджана. Автореф. дис. ... канд. биол. наук. Баку, 28 с.

27. Степанова О.Н. 2016. Фауна и численность пухоедов (Insecta: Phthiraptera), паразитирующих на оседлых видах воробьинообразных птиц Aves: Passeriformes)) Якутии. Паразитология, 50 (5): 387-394.

28. Степанова О.Н. 2019а. Материалы к фауне пухоедов (Phthiraptera, Ischnocera: Degeeriellidae, Esthiopteridae) птиц Сибири. Русский орнитологический журнал, 28 (1846): 5228-5234.

29. Степанова О.Н. 2019б. Материалы к фауне пухоедов (Phthiraptera, Amblycera: Menoponidae, Laemobothriidae, Pseudomenoponidae) птиц Сибири // Русский орнитологический журнал, 28 (1716): 43-49.

30. Тебуева О.М. 2011. Фауна, зоогеография и специфичность отношений с хозяевами пухоедов (Mallophaga) Центрального Предкавказья. Дис. ... канд. биол. наук. Ставрополь, 173 с.

31. Теуэльде Р.Т., Гапонов С.П. 2020. Паразитические насекомые в гнездах Passer domesticus (Linnaeus, 1758) и P. montanus (Linnaeus, 1758) (Aves, Passeriformes) в г. Воронеже. Полевой журнал биолога, 2 (2): 48-60.

32. Толстенков О. О., Алексеев А. Н., Дубинина Е. В. 2009. Пухоеды-гематофаги (Insecta: Phthiraptera, Amblycera) и клещи (Acari, Ixodidae) перелетных птиц Куршской косы. Поволжский экологический журнал, 4: 327-336.

33. Федоренко И.А. 1976. Материалы к фауне пухоедов воробьиных птиц Украины. Сообщение II. Brueliinae (Mallophaga, Ischnocera). Ч. II. Вестник зоологии, (6): 42-47.

34. Федоренко И.А. 1977. Материалы к фауне пухоедов воробьиных птиц Украины: Сообщение 3. Philopterinae (Mallophaga, Ischnocera). Ч. 1. Вестник зоологии, (6): 33-38.

35. Федоренко И.А. 1978. Материалы к фауне пухоедов воробьиных птиц Украины: Сообщение 4. Philopterinae (Mallophaga, Ischnocera). Ч. 2. Вестник зоологии, (2): 55-60.

36. Федоренко И.А. 1983. Новые виды рода Philopterus (Mallophaga, Philopteridae) от каменок фауны СССР. Вестник зоологии, (1): 27-33.

37. Федоренко И.А. 1987. Пухоеды. Фауна Украины. Киев, Наукова думка, 165 с. 
38. Федоренко И.А., Бельская Г.С., Кекилов а А.Ф., Сухинин А.Н. 1975. К фауне пухоедов (Mallophaga) некоторых птиц южной Туркмении (преимущественно воробьиных и хищных). Известия АН СССР. Серия биологических наук, 78: 1-72.

39. Федоренко И.А., Харченко В.И. 1980. К изучению пухоедов (Mallophaga) хищных птиц Европейской части СССР. В кн.: IX конференция Украинского паразитологического общества. Тезисы докладов. Часть 4. Киев: 114-115.

40. Чвак Г.В., Харамбура Л.И. 1972. К фауне пухоедов воробьиных птиц Черногоры (Украинские Карпаты). Проблемь паразитологии, 4 (2): 400-402.

41. Чернобай В.Ф. 1972. К проблеме хозяино-паразитарной специфичности. Проблемы паразитологии 4 (20): 408-410.

42. Adam C., Chiçamera G., Daraczi S.J., Sandor A.D., Gogu-Bogdan M. 2009. Data on the Chewing louse fauna (Phthiraptera, Amblycera, Ischnocera) from some wild and domestic birds of Romania. Travaux du Museum National d'Histoire Naturelle «Grigore Antipa», 52: 117-232.

43. Adam C., Sandor A.D. 2004. New data on the Chewing louse fauna (Phthiraptera, Amblycera, Ischnocera) from Romania. Pt I. Travaux du Musuum National d'Histoire Naturelle "Grigore Antipa», 46: 75-82.

44. Adam C., Sandor A.D. 2005. New data on the Chewing louse fauna (Phthiraptera, Amblycera, Ischnocera) from Romania. Pt II. Travaux du Musuum National d'Histoire Naturelle "Grigore Antipa», 48: $65-86$.

45. Clay T. 1970. The Amblycera (Phthiraptera: Insecta). Bulletin of the British museum (Natural history) Entomology, 25: 75-98.

46. Diakou A., Pedroso Couto Soares J.B., Alivizatos H., Panagiotopoulou M., Kazantzidis S., Literák I., Sychr O. 2017. Chewing lice from wild birds in northern Greece. Parasitology International, 66 (5): 699-706.

47. Emerson K.C. 1972a. Checklist of the Mallophaga of North America (North of Mexico) Part. I. Suborder Ischnocera. Dugway, Utah, 200 p.

48. Emerson K.C. 1972b. Checklist of the Mallophaga of North America (North of Mexico) Part. II. Suborder Amblycera. Dugway, Utah, 118 p. $178-191$.

49. Frank N.Y., Kritsky G. 2002. The Hemipteroidea. In: A Survey of Entomology. iUniverse:

50. Galloway T.D. 2019. Phthiraptera of Canada. Zookeys, (819): 301-310.

51. Guevara Pozo D., Guevara Benitez D.C., Soler Cruz M.D. 1981. Menacanthus annulatus Giebel, 1874 and Philopterus fringillae Denny, 1842 (Mallophaga) parasites of Passer domesticus L. Instituto Nacional de Investigación y Tecnología Agraria y Alimentaria, 79 (1-4): 129-137.

52. Ilieva M.N. 2005. New data on chewing lice (Insecta: Phthiraptera) from wild birds in Bulgaria. Acta Zoologica Bulgarica., 57(1): 37-48.

53. Johnson K.P., Clayton D.H. 2003. The biology, ecology and evolution of chewing lice. In: The chewing lice: World checklist and biological overview. Illinois Natural History Survey Special publication 24: 1-25.

54. Price R. 1975. The Menacanthus eurysternus Complex (Mallophaga: Menoponidae) of the Passeriformes and Piciformes (Avec). Annals of the Entomological Society of America, 68 (4): 617-662.

55. Price R. 1977. The Menacanthus (Mallophaga: Menoponidae) of the Passeriformes (Avec). Journal Medical Entomology, 14 (2): 207-220.

56. Price R.D., Hellenthal R.A., Palma R.L. 2003. The chewing lice: world checklist and biological overview. Illinois Natural History Society, 24: 1-448.

57. Price R.D, Hellenthal R.A, Palma R.L., Johnson K.P., Clayton D.H. 2003. The chewing lice: World checklist and biological overview. Illinois, $501 \mathrm{p}$.

58. Soler-Cruz M.P., Benitez-Rodríguez R., Alcantara-Ibanez F., Florido-Navío A.M., Muñoz-Parra S. 1989. List of species of the Mallophaga found in Spain. Angewandte Parasitologie, 35 (2): 168-173.

59. Stepanova O.N. 2018. Materials on the fauna of feather lice of Siberian Birds (Phthiraptera, Amlycera, Ancistronidae, Laemobothriidae, Pseudomenoponidae). Russian Journal of Ornithology, 27 (1686): 5253-6263.

60. Sychra O., Literák I., Podzemný P., Harmat P., Hrabák R. 2011. Insects ectoparasites on wild birds in the Czech Republic during the pre-breeding period. Ectoparasites on wild birds in central Europe, 18: 13-19. 
61. Złotorzycka J. 1964. Mallophaga parasitizing Passeriformes and Pici. Pt 3. Philopterinae. Acta Parasitologica Polonica, 12 (37): 401-432.

62. Złotorzycka J. 1980. Kluze do oznaczania owadow Polski. Cz. 15. Wszoly Mallophaga. Zes. 5. Nadrodzina Philopteroidea: rodzina Mrinertzhagemellidae, Lipeuridae, Degeeriellidae, Pseudonirmidae, Giebellidae, Esthiopteridae I Acidoproctidae. Warszawa - Wroclaw, P.W.N., 202 p.

63. Złotorzycka J. 1983. Mallophagenfunde aus Vogeln und Saugetieren in zoologischen Garten. Angewandte Parasitologie, 24: 166-178.

\section{References}

1. Balashov Yu.S. 2001. Specificity of host-parasite relationships between arthropods and terrestrial vertebrates. Parasitology, 35 (6): 473-489. (in Russian)

2. Bej-Bienko G.Ya. (gen. ed.). 1964. Opredelitel nasekomyh Evropejskoj chasti SSSR. T. 1. Nizshie, drevnekrylye, s nepolnym prevrasheniem [Keys to insects of the European part of the USSR. T. 1. Lower, ancient winged, with incomplete transformation]. Moscow-Leningrad, Nauka, 936 p.

3. Blagoveshenskij D.I. 1940a. Mallophaga s ptic Talysha [Mallophaga of Talysh birds]. Parazitologicheskij sbornik, (8): 25-90.

4. Blagoveshenskij D.I. 1940б. Fauna SSSR. Opredelitel puhoedov (Mallophaga) domashnih zhivotnyh [Fauna of the USSR. Keys to poultry lice (Mallophaga) of domestic animals]. Moscow, $88 \mathrm{p}$.

5. Blagoveshenskij D.I. 1948. Mallophaga s ptic Barabinskih ozer [Mallophaga of birds of Baraba lakes]. Parazitologicheskij sbornik, (10): 259-294.

6. Blagoveshenskij D.I. 1950. Mallophaga s ptic Barabinskih ozer [Mallophaga of birds of Baraba lakes]. Parazitologicheskij sbornik, (12): 87-122.

7. Blagoveshenskij DI. 1951. Mallophaga Tadzhikistana [Mallophaga of Tajikistan]. Parazitologicheskij sbornik, (13): 272-327.

8. Blagoveshenskij D.I. 1964. Opredelitel nasekomyh Evropejskoj chasti SSSR [Keys to insects of the European part of the USSR]. T. 1. Moscow-Leningrad, Nauka: 309-323.

9. Vasyukova T.T. 1986. Puhoedy (Mallophaga) vodno-bolotnyh ptic Yakutii [Puff lice (Mallophaga) of waterbirds of Yakutia]. Yakutsk, $116 \mathrm{p}$.

10. Vasyukova T.T., Komarov Yu.E. 1997. Materials for the fauna of chewing lice and feather mites of some bird species of the Republic of North Ossetia - Alania. Kavkazskij ornitologicheskij vestnik. Stavropol, (9): 5-19.

11. Volkis G.I., Panavajte M.A. 1965. Materialy k faune puhoedov ptic Litovskoj SSR [Materials for the fauna of chewing lice birds of the Lithuanian SSR.]. Trudy Akademii nauk Litovskoy SSR, (38): 97-107.

12. Gaponov S.P. 2011. Parazitologiya [Parasitology]. Voronezh, Voronezh State University Publishing House, 732 p.

13. Gaponov S.P., Hicova L.N., Solodovnikova O.G. 2009. Metody parazitologicheskikh issledovaniy [Parasitological research methods]. Voronezh, VGU, $180 \mathrm{p}$.

14. Grinberge A.R. 1974. Dannye o puhoedah vranovyh ptic v Latvii [Data on chewing lice of corvids in Latvia]. Latviyskaya entomologiya, (16): 14-20.

15. Dogel V.A. 1949. Biologicheskie osobennosti parazitofauny pereletnyh ptic [Biological features of the parasite fauna of migratory birds]. Izvestiya AN SSSR, Seriya biologicheskaya, (1): 99-107.

16. Dogel V.A., Navtsevich N.D. 1936. Parazitofauna gorodskoj lastochki. K voprosu o proishozhdenii parazitofauny pereletnyh ptic [Parasite fauna of the city swallow. On the issue of the origin of the parasite fauna of migratory birds]. Uchenyye zapiski LGU, Seriya biologicheskaya, 7 (3): 80-113.

17. Dubinin V.B. 1948. Issledovanie adaptacij ektoparazitov. II. Ekologicheskie adaptacii perevyh kleshej i puhoedov [Study of adaptations of ectoparasites. II. Ecological adaptations of feather mites and lice]. Parazitologicheskiy sbornik Zoologicheskogo instituta AN SSSR, 9: 191-222.

18. Zhuk E.Yu. 2009. Faunisticheskie kompleksy puhoedov ptic Belarussii [Faunistic complexes of chewing lice of birds of Belarus]. Trudy Stavropolskogo otdeleniya Russkogo entomologicheskogo obshestva, (5): 55-56.

19. Kadastr bespozvonochnyh zhivotnyh Voronezhskoj oblasti [Cadastre of invertebrates in the Voronezh region]. 2005. Voronezh, VGU, 825 p. 
20. Lyahova O.M. 2006. Pukhoyedy (Mallophaga) Tsentral'nogo Predkavkaz'ya [Puff lice (Mallophaga) of the Central Ciscaucasia]. In: Materials of the 1st All-Russian meeting on blood-sucking insects. Saint-Petersburg: 114-116.

21. Lyahova O.M., Kotti B.K. 2010. Puff lice (Mallophaga: Insecta) on birds in the Central Ciscaucasia. Parasitology, 44 (5): 461-474. (in Russian)

22. Malysheva O.D., Tolstenkov O.O. 2018. Puff lice (Insecta, Phthiraptera) of migratory birds of the Curonian Spit. Parasitology, 52 (2): 118-136. (in Russian)

23. Malysheva O.M., Zabashta A.V., Tolstenkov O.O. 2018. To the fauna of down-eating lice (Insecta: Phthiraptera) birds (Aves: Falconiformes, Strigiformes) of the Lower Don, Russia. Caucasian Entomological Bulletin, 14 (1): 11-18. (in Russian)

24. Malysheva O.D., Zabashta A.V., Tolstenokov O.O. 2018. To the fauna of puff lice (Phthiraptera) birds of the Lower Don, Russia. Puff lice non-passerines. Part 1. Caucasian Entomological Bulletin, 14 (2): 131-139. (in Russian)

25. Medvedev S.G. 2002. Peculiarities of distribution and host-parasite relationships of fleas (Siphonaptera). Entomological Review, 81 (3): 737-753. (in Russian)

26. Mustafaeva Z.A. 1972. Ektoparazity sinantropnyh i domashnih ptic Azerbajdzhana [Ectoparasites of synanthropic and domestic birds of Azerbaijan]. Abstract, dis. ... cand. biol. sciences.. Baku, $28 \mathrm{p}$.

27. Stepanova O.N. 2016. Fauna and number of chewing lice (Insecta: Phthiraptera) parasitizing on sedentary species of passerine birds Aves: Passeriformes)) of Yakutia. Parasitology, 50 (5): 387-394. (in Russian)

28. Stepanova O.N. 2019a. Materials for the fauna of chewing lice (Phthiraptera, Ischnocera: Degeeriellidae, Esthiopteridae) of Siberian birds. Russian Ornithological Journal, 28 (1846): 5228-5234. (in Russian)

29. Stepanova O.N. 20196. Materials to the fauna of chewing lice (Phthiraptera, Amblycera: Menoponidae, Laemobothriidae, Pseudomenoponidae) birds of Siberia. Russian Ornithological Journal, 28 (1716): 43-49. (in Russian)

30. Tebueva O.M. 2011. Fauna, zoogeografiya i spetsifichnost' otnosheniy s khozyayevami pukhoyedov (Mallophaga) Tsentral'nogo Predkavkaz'ya [Fauna, zoogeography and specificity of relations with the owners of the chewing lice (Mallophaga) of the Central Ciscaucasia]. Dis. .... cand. biol. sciences. Stavropol, $173 \mathrm{p}$.

31. Tewelde R.T., Gaponov S.P. 2020. Insect Parasites Inhabiting Passer domesticus (Linnaeus, 1758) and P. montanus (Linnaeus, 1758) (Aves: Passeriformes) Nests in Voronezh. Field Biologist Journal, 2 (2): 48-60. (in Russian)

32. Tolstenkov O.O., Alekseev A.N., Dubinina E.V. 2009. Hematophagous chewing lice (Insecta: Phthiraptera, Amblycera) and ticks (Acari, Ixodidae) of migratory birds of the Curonian Spit. Povolzhskiy Journal of Ecology, 4: 327-336. (in Russian)

33. Fedorenko I.A. 1976. Materials for the fauna of the passerine birds of Ukraine. Communication II. Brueliinae (Mallophaga, Ischnocera). Part II. Vestnik zoologii, (6): 42-47. (in Russian)

34. Fedorenko I. A. 1977. Materials for the fauna of chewing lice in passerines of Ukraine: Communication 3. Philopterinae (Mallophaga, Ischnocera). Part 1. Vestnik zoologii, (6): 33-38. (in Russian)

35. Fedorenko I. A. 1978. Materials for the fauna of the passerine birds of Ukraine: Communication 4. Philopterinae (Mallophaga, Ischnocera). Part 2. Vestnik zoologii, (2): 55-60. (in Russian)

36. Fedorenko I. A. 1983. New species of the genus Philopterus (Mallophaga, Philopteridae) from wheats of the USSR fauna. Vestnik zoologii, (1): 27-33. (in Russian)

37. Fedorenko I. A. 1987. Puhoedy. Fauna Ukrainy [Pooh-eaters. Fauna of Ukraine]. Kiev, Naukova Dumka, 165 p.

38. Fedorenko I. A., Belskaya G. S., Kekilov a A. F., Suhinin A. N. 1975. K faune puhoedov (Mallophaga) nekotoryh ptic yuzhnoj Turkmenii (preimushestvenno vorobinyh i hishnyh) [To the fauna of the chewing lice (Mallophaga) of some birds of southern Turkmenistan (mainly passerines and carnivores)]. Izvestiya AN SSSR. Seriya biologicheskih nauk, 78 : 1-72.

39. Fedorenko I.A., Harchenko V.I. 1980. K izucheniyu puhoedov (Mallophaga) hishnyh ptic Evropejskoj chasti SSSR [To the study of chewing lice (Mallophaga) birds of prey of the European part of the USSR]. In: IX konferentsiya Ukrainskogo parazitologicheskogo obshchestva [IX conference of the Ukrainian Parasitological Society]. Abstracts of reports. Part 4. Kiev: 114-115. 
40. Chvak G.V., Harambura L.I. 1972. K faune puhoedov vorobinyh ptic Chernogory (Ukrainskie Karpaty) [To the fauna of chewing lice of passerine birds of Chernogory (Ukrainian Carpathians)]. Problemy parazitologii, 4 (2): 400-402.

41. Chernobaj V.F. 1972. K probleme hozyaino-parazitarnoj specifichnosti [On the problem of host-parasitic specificity]. Problemy parazitologii, 4 (20): 408-410.

42. Adam C., Chiçamera G., Daraczi S.J., Sandor A.D., Gogu-Bogdan M. 2009. Data on the Chewing louse fauna (Phthiraptera, Amblycera, Ischnocera) from some wild and domestic birds of Romania. Travaux du Museum National d'Histoire Naturelle "Grigore Antipa», 52: $117-232$.

43. Adam C., Sandor A.D. 2004. New data on the Chewing louse fauna (Phthiraptera, Amblycera, Ischnocera) from Romania. Pt I. Travaux du Musuum National d'Histoire Naturelle "Grigore Antipa», 46: 75-82.

44. Adam C., Sandor A.D. 2005. New data on the Chewing louse fauna (Phthiraptera, Amblycera, Ischnocera) from Romania. Pt II. Travaux du Musuum National d'Histoire Naturelle «Grigore Antipa», 48: $65-86$.

45. Clay T. 1970. The Amblycera (Phthiraptera: Insecta). Bulletin of the British museum (Natural history) Entomology, 25: 75-98.

46. Diakou A., Pedroso Couto Soares J.B., Alivizatos H., Panagiotopoulou M., Kazantzidis S., Literák I., Sychr O. 2017. Chewing lice from wild birds in northern Greece. Parasitology International, 66 (5): 699-706.

47. Emerson K.C. 1972a. Checklist of the Mallophaga of North America (North of Mexico) Part. I. Suborder Ischnocera. Dugway, Utah, 200 p.

48. Emerson K.C. 1972b. Checklist of the Mallophaga of North America (North of Mexico) Part. II. Suborder Amblycera. Dugway, Utah, 118 p.

49. Frank N.Y., Kritsky G. 2002. The Hemipteroidea. In: A Survey of Entomology. iUniverse: $178-191$.

50. Galloway T.D. 2019. Phthiraptera of Canada. Zookeys, (819): 301-310.

51. Guevara Pozo D., Guevara Benitez D.C., Soler Cruz M.D. 1981. Menacanthus annulatus Giebel, 1874 and Philopterus fringillae Denny, 1842 (Mallophaga) parasites of Passer domesticus L. Instituto Nacional de Investigación y Tecnología Agraria y Alimentaria, 79 (1-4): 129-137.

52. Ilieva M.N. 2005. New data on chewing lice (Insecta: Phthiraptera) from wild birds in Bulgaria. Acta Zoologica Bulgarica., 57(1): 37-48.

53. Johnson K.P., Clayton D.H. 2003. The biology, ecology and evolution of chewing lice. In: The chewing lice: World checklist and biological overview. Illinois Natural History Survey Special publication 24: 1-25.

54. Price R. 1975. The Menacanthus eurysternus Complex (Mallophaga: Menoponidae) of the Passeriformes and Piciformes (Avec). Annals of the Entomological Society of America, 68 (4): 617-662.

55. Price R. 1977. The Menacanthus (Mallophaga: Menoponidae) of the Passeriformes (Avec). Journal Medical Entomology, 14 (2): 207-220.

56. Price R.D., Hellenthal R.A., Palma R.L. 2003. The chewing lice: world checklist and biological overview. Illinois Natural History Society, 24: 1-448.

57. Price R.D, Hellenthal R.A, Palma R.L., Johnson K.P., Clayton D.H. 2003. The chewing lice: World checklist and biological overview. Illinois, $501 \mathrm{p}$.

58. Soler-Cruz M.P., Benitez-Rodríguez R., Alcantara-Ibanez F., Florido-Navío A.M., Muñoz-Parra S. 1989. List of species of the Mallophaga found in Spain. Angewandte Parasitologie, 35 (2): 168-173.

59. Stepanova O.N. 2018. Materials on the fauna of feather lice of Siberian Birds (Phthiraptera, Amlycera, Ancistronidae, Laemobothriidae, Pseudomenoponidae). Russian Journal of Ornithology, 27 (1686): 5253-6263.

60. Sychra O., Literák I., Podzemný P., Harmat P., Hrabák R. 2011. Insects ectoparasites on wild birds in the Czech Republic during the pre-breeding period. Ectoparasites on wild birds in central Europe, 18: 13-19.

61. Złotorzycka J. 1964. Mallophaga parasitizing Passeriformes and Pici. Pt 3. Philopterinae. Acta Parasitologica Polonica, 12 (37): 401-432. 
62. Złotorzycka J. 1980. Kluze do oznaczania owadow Polski. Cz. 15. Wszoly Mallophaga. Zes. 5. Nadrodzina Philopteroidea: rodzina Mrinertzhagemellidae, Lipeuridae, Degeeriellidae, Pseudonirmidae, Giebellidae, Esthiopteridae I Acidoproctidae. Warszawa - Wroclaw, P.W.N., 202 p.

63. Złotorzycka J. 1983. Mallophagenfunde aus Vogeln und Saugetieren in zoologischen Garten. Angewandte Parasitologie, 24: 166-178.

Поступила в редакиию 10.09.2020

\section{Ссылка для цитирования статьи}

\section{For citation}

Гапонов С.П., Теуэльде Р.Т. 2020. Фауна пухоедов (Phthiraptera: Mallophaga) воробьинообразных птиц в г. Воронеже. Полевой журнал биолога, 2 (3): 205-218. DOI 10.18413/2658-3453-2020-2-3-205-218

Gaponov S.P., Tewelde R.T. 2020. Fauna of the Chewing Lice (Phthiraptera: Mallophaga) of Passerine Birds in Voronezh. Field Biologist Journal, 2 (3): 205-218. DOI 10.18413/2658-3453-2020-23-205-218 